\title{
Editorial. Troubler et inquiéter : les discours du désordre international
}

Jean-Yves Haine

\section{OpenEdition}

\section{Journals}

Édition électronique

URL : http://journals.openedition.org/conflits/487

DOI : $10.4000 /$ conflits.487

ISSN : $1777-5345$

Éditeur :

CCLS - Centre d'études sur les conflits lilberté et sécurité, L'Harmattan

Édition imprimée

Date de publication : 15 octobre 1995

ISSN : 1157-996X

Référence électronique

Jean-Yves Haine, «Editorial. Troubler et inquiéter : les discours du désordre international », Cultures \&

Conflits [En ligne], 19-20 | automne-hiver 1995, mis en ligne le 10 mars 2003, consulté le 30 mars

2021. URL : http://journals.openedition.org/conflits/487 ; DOI : https://doi.org/10.4000/conflits.487

Ce document a été généré automatiquement le 30 mars 2021.

Creative Commons License 


\title{
Editorial. Troubler et inquiéter : les discours du désordre international
}

\author{
Jean-Yves Haine
}

1 Certains historians find certains periods of history nothing intelligible, and call them dark ages; but such phrases tell us nothing about the ages themselves, though they tell us a great deal about the persons who use them.

R. G. Collingwood, « The idea of history », 1946

3 Comme le signalait Jean Delumeau, la sécurité a toujours consisté à rassurer et protéger ${ }^{1}$. Mais que se passe-t-il lorsque s'effondrent les croyances les plus enracinées dans l'esprit, celles qui fondent le sens que l'on donne au monde? Des peurs, des inquiétudes face à un monde soudainement incompréhensible émergent. Elles s'expriment soit brutalement, soit à travers des discours qui les prennent en charge, les rationalisent. Loin de les faire disparaître, ces discours en tirent leur ressort et font de ces peurs, une lecture du monde. Ce dernier, bien que relativement inchangé se voit investi de nouvelles significations. Il est dangereux, inquiétant, troublant, chaotique. Il nécessite de la part des hommes une adaptation mais aussi une reprise en main. Il faut plus de sécurité qu'auparavant, plus d'ordre, plus d'obéissance aux institutions.

4 Jean Delumeau parlait en historien, nous rappelant les peurs de l'occident entre le XIVème et le XVIIème siècle ${ }^{2}$. Osons un parallèle. Que se passe-t-il depuis la fin de la bipolarité ? Le monde a-t-il radicalement changé ou est-ce sa lecture ? Les conflits ontils à ce point été modifié sur la planète qu'à l'ordre et la stabilité de la période bipolaire succéderait le chaos, le trouble, l'instabilité, le désordre post bipolaire? Certes les conflits ont connu des métamorphoses assez significatives dont l'une des plus importantes est sans doute d'être moins enchevêtrés qu'auparavant maintenant que l'enveloppe de l'affrontement Est-Ouest n'existe qu'à un degré moindre ${ }^{3}$. Mais les transformations de la conflictualité les plus significatives en terme d'acteurs (étatiques ou non), en terme de relations entre les acteurs militarisés et les populations civiles sont bien antérieures à la fin de la bipolarité ${ }^{4}$. Seulement la lecture de ces conflits, elle, a changé depuis la fin de la bipolarité. Auparavant stratèges, hommes politiques, spécialistes de relations internationales avaient tendance dans leur majorité à 
considérer selon un point de vue globaliste que les conflits hors de la sphère occidentale étaient les produits de stratégies indirectes entre l'Est et l'Ouest. Survalorisant le rôle des grandes puissances, de l'idéologie, des ressources extérieures mises à disposition des belligérants, ils occultaient les dynamiques locales et transnationales, la prédation sur les populations, les ressources internes et celles liées aux trafics de produits illicites. Autant de traits qu'ils redécouvrent maintenant et qu'ils portent au crédit de la fin de la stabilité bipolaire. De même, le discours nostalgique sur la stabilité bipolaire évacue-t-il les critiques sur la domination, la coercition des populations dans l'orbite soviétique et le fait que pour certaines de ses populations, la liberté retrouvée a aussi été la liberté de protester et de se battre. La fin d'un ordre coercitif n'est pas prise en considération dans le bilan global de la conflictualité comme si les répressions d'Etat n'étaient pas aussi mortifères et politicides que les conflits ouverts. Cette vision pour le moins étroite des conflits amène alors à penser que les conflits se sont multipliés sur la planète depuis 1990 alors que si les conflits ouverts se sont développés et surtout médiatisés, les populations soumises à des répressions d'Etat sont moins nombreuses.

5 Les discours sur le désordre international renvoient donc plus au trouble dans les esprits des analystes qu'aux transformations de la conflictualité. Le trouble tient moins à un paysage international brouillé par les conflits qu'à des jugements de valeurs pris aux pièges de leurs anciennes certitudes et déconcertés de les voir s'effondrer. Les métaphores sur le chaos, le désordre relèvent, non d'une nouvelle problématique tirée des sciences physiques et d'une nouvelle compréhension du monde, mais des réactions d'angoisse des professionnels de la sécurité face à la perte de leurs repères routiniers, établis parfois en dogmes par les internationalistes. Les textes que nous publions ici reviennent tous de manière critique sur la nouvelle doxa qui s'institue et sur les conditions de son apparition. La caricature du passé, brusquement valorisé, permet à des discours d'insécurisation de se déployer pour demander toujours plus de sécurisation. Que la bipolarité était belle! Les discours alarmistes sur le présent ne cessent de faire référence à un ordre international, rêvé plus que vécu, et qui, rétrospectivement leur semble un paradis perdus : une diplomatie basée sur le dialogue entre chefs d'Etats responsables, prudents et surtout n'ayant pas de compte à rendre à leur population, un cadre international où les grandes puissances pouvaient s'entendre entre elles tout en contrôlant leur alliés, une stabilité garantie par des arsenaux nucléaires et une bipolarité assurant une longue période de non guerre. Le changement n'est pas paradigmatique, bien au contraire. Le désordre contemporain n'existe qu'en référence à l'ordre perdu. L'international, bouc-émissaire d'autant plus facilement désigné qu'il est moins lisible, demeure le lieu de l'éternelle anarchie, mais il est doté cependant d'un "danger» supplémentaire proprement contemporain et particulièrement pernicieux qui menacerait aujourd'hui la stabilité du contrat social : l'anarchie contagieuse gagnerait la sphère interne et attaquerait désormais le cœur des sociétés modernes. L'Etat ne s'en relèverait pas et tout flux transnational quelqu'il soit deviendrait une menace. Anarchie interne, zones grises, nouveau moyen âge, violences diffuses, la guerre occuperait l'horizon interne et international. Le temps du Chaos serait advenu.

6 Peut-on pour autant prédire un «bel avenir à la guerre "? Sans verser dans la béatitude kantienne, il convient d'abord de réfléchir sur les changements d'acteurs et sur la nature de la politique internationale, avant de prédire avec la fin d'un soi-disant ordre ancien, l'émergence inévitable d'un désordre nouveau ${ }^{5}$. Le remplacement de la 
"power politics" par ce que Stanley Hoffmann appelle la "people politics" ne contient pas, en soi, plus de germes de déstabilisation que le concert bipolaire que l'on se complaît à regretter. La démocratisation de l'international ne signifie pas le chaos et le clash civilisationnel, n'en déplaisent aux professionnels du monde de la sécurité.

\section{NOTES}

1. . Jean Delumeau, Rassurer et protéger, Paris, Fayard, 1989.

2. . Jean Delumeau, La peur en Occident, Paris, Fayard, 1978.

3. . Didier Bigo, Daniel Hermant, « La métamorphoses des conflits » in Etudes Polémologiques, $n^{\circ} 50,2 / 89$.

4. . « Les conflits après la bipolarité », Cultures \& Conflits, n8, hiver 1992.

5. . Ce sera l'objet de deux autres numéros de Cultures \& Conflits : l'un sur

l'international sans territoire, l'autre sur les stratégies de survie en situation de crise.

\section{INDEX}

Mots-clés : (in)sécurité, menace, Relations Internationales

Index chronologique : post-guerre froide 